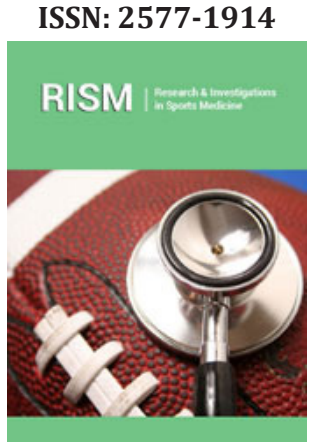

*Corresponding author: mgr Jan Adamczyk, Department of Gymnastics, Poznań University of Physical Education, Poland

Submission: 此 December 05, 2019

Published: 侮 April 16, 2020

Volume 6 - Issue 2

How to cite this article: Piotr Gronek, Tomasz Banasiewicz, Roman Celka, Jan Adamczyk, et al. On the Road to Recovery: Do I/D Polymorphisms in the ACE Gene have a Part to Play?. Res Inves Sports Med, 6(2): RISM.000634. 2020

DOI: $10.31031 /$ RISM.2020.06.000634

Copyright@ Jan Adamczyk, This article is distributed under the terms of the Creative Commons Attribution 4.0 International License, which permits unrestricted use and redistribution provided that the original author and source are credited.

\section{On the Road to Recovery: Do I/D Polymorphisms in the ACE Gene have a Part to Play?}

\author{
Piotr Gronek ${ }^{1}$, Tomasz Banasiewicz ${ }^{2}$, Maciej Borejsza-Wysocki², Roman \\ Celka $^{3}$, Jan Adamczyk ${ }^{3 *}$, Michał Boraczyński ${ }^{4}$, Cain CT Clark ${ }^{5}$, Maria Tarnas ${ }^{1}$, \\ Agata Wiza ${ }^{6}$ and Joanna Gronek ${ }^{1}$
}

${ }^{1}$ Laboratory of Genetics, Department of Dance and Fitness, Poznań University of Physical Education, Poznań, Poland

${ }^{2}$ Department of General and Endocrine Surgery and Gastroenterological Oncology, Poznań University of Medical Sciences, Poznań, Poland

${ }^{3}$ Department of Gymnastics, Poznań University of Physical Education, Poznań, Poland

${ }^{4}$ Department of Health Sciences, Olsztyn University College, Olsztyn, Poland

${ }^{5}$ Faculty of Health and Life Sciences, Coventry University, Coventry, CV1 5FB, United Kingdom

${ }^{6}$ Department of Pedagogy, Poznań University of Physical Education, Poznań, Poland

\begin{abstract}
The serum angiotensin converting enzyme (ACE) level in individuals with a DD genotype is two-fold higher than those with an II genotype. The DD genotype is correlated with a higher risk of cardiovascular diseases, lower adaptability to hypoxic conditions, as well as lower cardio-respiratory capacity. The aim of the study was to examine the role of I/D polymorphisms in the ACE gene in surgical patients vs. healthy, active individuals. Two groups were investigated in the study: 91 surgical patients and 39 physically active controls. The level of adaptation to physical stress, compensating processes, and sense of well-being of participants were determined with subjective and objective inferential methods. Additionally, the represented ACE gene polymorphism was evaluated using molecular analyses.
\end{abstract}

The role of the DD vs. II genotype is unclear in healthy, active individuals. Whilst in patients who regularly participated in sport accrued shorter hospital stay time $(\mathrm{P}=0.04)$. The type of surgery performed significantly affects patients' time to convalescence $(\mathrm{P}=0.03)$. Patients' time in hospital after oncological surgeries is longer, regardless of whether chemotherapy was received or not. Based on the collected data, it was not possible to indicate a common genotype predisposing resistance to physical stress in both examined groups, with no statistically significant correlation between the ID polymorphism of ACE gene in either group. However, the noted tendencies may suggest a role of allele I and II genotypes in patient convalescence and as such, necessitates further investigation.

Keywords: Genotype; Maximal intensity effort; Climbers; Surgical patients

\section{Introduction}

Since 1923, maximal oxygen uptake $\left(\dot{\mathrm{VO}}_{2 \max }\right)$ has referred to the oxygen uptake attained during maximal intensity exercise that could not be increased despite further exercise workload increments, thereby defining the limits of the cardio respiratory system. Surgical intervention requires the human body to undergo high physical stress, including hypoxia, which influences tissue regeneration after surgery as a consequence of an oxygen delivery versus consumption mismatch that occurs when cell proliferation exceeds neoangiogenesis [1]. Hypoxia inhibits, or even prohibits, continuing physical and intellectual activity during and post-surgical interventions, contributing to the prolongation of tissue recovery and patient's general convalescence. Interestingly, in Rossetti et al. [2], physically active individuals, with greater sea-level fitness levels, reported less strenuous effort during simulated and actual physical activities, had better mood levels (less fatigue), and chose a higher step rate during perceptually regulated exercise, and did not suffer from any worsened arterial oxygen desaturation. Comparatively, surgical patients with acceptable levels of 
endurance performance are shown to recover, relatively better, are discharged home earlier, and return to their daily activities sooner than patients with low levels [3].

The capacity to perform endurance exercise and, consequently, physical resistance is asserted to be genetically conditioned [4]. Genetic factors have an essential influence over components of the athletic performance such as elite athlete status [5], some of motor skills [6], endurance [7], maximal oxygen uptake [8-10], increased risk of injurence [11], resistance to pain [12] or determinants of aggression in sport [13] and other phenotypes.

Among 200 single nucleotide polymorphisms (SNP) associated with physical performance, the angiotensin-converting enzyme (ACE) gene is one of most frequently investigated [14]. The ACE converts angiotensin I to angiotensin II. This entails blood vessels narrowing in diameter, and results in increased blood pressure. Functionally, the most significant is intron 16 of the human ACE gene (location: 17q23.3) where a 287 bp Alu sequence insertion fragment (I allele) and deletion fragment (D allele) were recognized [15]. Significant differences between genotypes II and DD were observed in terms of blood pressure. The ACE gene is the most intensively examined gene in view of athletic performance, especially endurance performance, particularly given the importance of blood pressure during prolonged and intense exercise [16]. Allele I is overrepresented among active individuals who practice endurance sports [17].

Whether healthy and active, or suffering through ill-health, the interest among both populations for recovery, fitness and adaptation is of paramount importance [18]. The serum ACE level in individuals with a DD genotype is two-fold higher than those with an II genotype and is correlated with a higher risk of cardiovascular diseases, lower adaptability to hypoxic conditions, as well as lower cardio-respiratory capacity, it was therefore postulated that the existence of the II, DD or ID polymorphism may be associated with outcome and recovery in both populations. The aim of the study was to examine the role of I/D polymorphisms in the ACE gene

\section{Methods}

The study sample comprised surgical patients and physically active controls (described below) andwas conducted in accordance with the Declaration of Helsinki. The physically active group consisted of 39 male and female volunteers, ranging from professional climbers (ascended over $7000 \mathrm{~m}$ ) and recreational athletes, all of which met national physical activity guidelines. The group of patients underwent gastrointestinal surgeries and comprised 91 men and women of varied health status, aged 28 to 84 years. They were subdivided into 36 non-oncological surgery patients subjected to "medium" surgical procedures (cholecystectomy, stoma reversal, thyroid resection), and to "big" surgical procedures (colectomy, digestive tract reconstruction, adrenalectomy); and 55 oncological patients subjected to digestive tract tumor surgeries, who spent more time in hospital, and whose surgical procedures were more advanced and extensive. Additionally, 29 patients also underwent chemotherapy.

The study consisted of two parts: molecular analysis, and analysis of participants' health status and well-being, pre and post-surgery and physical activity, respectively. All participants gave their full written and informed consent to take part in the study. Participants' health status, fatigue level, and existing medical conditions and symptoms were evaluated using self-report questionnaires, whilst patients' course of post-operative recovery was analyzed in detail. The buccal cells were donated by participants with the use of sterile foam-tipped applicators (Puritan, USA). DNA was extracted using a GenElute Mammalian Genomic DNA Miniprep Kit (Sigma, Germany) according to the manufacturer's protocol. The samples were genotyped in duplicate. PCR amplification of the polymorphic region of the ACE gene containing either an insertion (I) or deletion (D) fragment was performed using a $\mathrm{T} 100^{\mathrm{TM}}$ Thermal Cycler (BioRad, Germany) instrument. One pair of primers (forward: CTG GAG ACC ACT CCC ATC CTT TCT, and reverse: GAT GTG GCC ATC ACA TTC GTC AGA) was used to determine the ACE genotype, yielding amplification products of approximately 490bp (for allele I) and $190 \mathrm{bp}$ (for allele D). PCR mixture and thermal-time profile were coequal as described by Cięszczyk et al. [17]. The amplified DNA fragments were visualized by using $1.5 \%$ agarose gels stained with ethidium bromide.

All statistical calculations were made with the use of the SAS ${ }$ ver. 9.3 software package (2013). The significance of experimental factors was determined with a multifactorial analysis of covariance according to the following linear models: for mountaineers yijkm = $\mathrm{si}+\mathrm{aj}+\mathrm{mk}+\mathrm{gl}+$ eijklm, where: yijkm- value of the analyzed trait, si - fixed effect of sex $(i=1,2)$, aj- fixed effect of age $(j=1,2)$, mk- fixed effect of mountaineer class $(\mathrm{k}=1,2)$, gl- fixed effect of genotype/ polymorphism $(l=1,2,3)$, eijklm - random error; and for patients yijkmno $=\mathrm{si}+\mathrm{aj}+\mathrm{zk}+\mathrm{cl}+\mathrm{pm}+\mathrm{gn}+$ eijklmno, where: yijkmnop value of the analyzed trait, si - fixed effect of sex ( $i=1,2)$, aj- fixed effect of age $(j=1,2)$, $z k$ - fixed effect of surgery type $(k=1,2), c l$ - fixed effect of chemotherapy treatment, pm - fixed effect of sport class ( $\mathrm{m}=1,2,3,4,5)$, gl- fixed effect of genotype/polymorphism (1 $=1,2,3$ ), eijklm - random error. Post-hoc Tukey test's for multiple comparisons were used to compare means for the items.

\section{Results}

The investigated polymorphism conformed to the HardyWeinberg equilibrium. A distribution of the genotypes and alleles in physically active individuals and patients is shown in Table 1. The ACE gene polymorphism was not shown to significantly affect wellbeing pre or post physical activity (Table 2). However, in the case of individuals with genotype II, well-being did not deteriorate post physical activity, while the tendency for well-being to decline was the highest for genotype DD. Neither class (amateur/professional) nor age (under or over 35 years) significantly affected well-being pre or post physical activity (Table 3 ). 
Table 1: Distribution of genotypes and alleles in healthy individuals and patients.

\begin{tabular}{|c|c|c|c|c|c|c|c|c|}
\hline & \multicolumn{4}{|c|}{ Healthy } & \multicolumn{4}{c|}{ Patients } \\
\hline Genotype & I/I & I/D & D/D & Total & I/I & I/D & D/D & Total \\
\hline Number of subjects & 1 & 23 & 15 & 39 & 10 & 51 & 30 & 91 \\
\hline Frequency of genotypes & 0.0256 & 0.5897 & 0.3846 & - & 0.1099 & 0.5604 & 0.3297 & - \\
\hline Allele frequency & 0.3205 & - & 0.6795 & - & 0.3901 & - & 0.6099 & - \\
\hline Expected frequency of genotypes & 0.1027 & 0.4356 & 0.4617 & - & 0.1522 & 0.4758 & 0.372 & - \\
\hline Number of subjects & 4 & 17 & 18 & 39 & 14 & 43 & 34 & - \\
\hline$\chi 2$ & 2.256 & 2.1283 & 0.502 & 4.8863 & 1.0697 & 1.3684 & 0.4377 & 2.8758 \\
\hline
\end{tabular}

Table 2: Comparative analysis between polymorphisms and participants' well-being.

\begin{tabular}{|c|c|c|c|c|c|c|}
\hline & & $\mathbf{p}$ & Polymorphism & $\mathbf{N}$ & $\overline{\mathbf{x}}$ & SD \\
\hline \multirow{6}{*}{ Healthy individuals } & \multirow{3}{*}{$\begin{array}{l}\text { Well-being pre } \\
\text { physical activity } \\
\text { (pts) }\end{array}$} & 0.21 & $\mathrm{I} / \mathrm{I}$ & 1 & 9 & - \\
\hline & & & I/D & 23 & 8.35 & 1.37 \\
\hline & & & $\mathrm{D} / \mathrm{D}$ & 15 & 7.4 & 0.99 \\
\hline & \multirow{3}{*}{$\begin{array}{l}\text { Difference in well- } \\
\text { being post physical } \\
\text { activity (pts.) }\end{array}$} & 0.98 & $\mathrm{I} / \mathrm{I}$ & 1 & 0 & - \\
\hline & & & $\mathrm{I} / \mathrm{D}$ & 23 & 0.13 & 1.25 \\
\hline & & & $\mathrm{D} / \mathrm{D}$ & 15 & 0.33 & 1.35 \\
\hline \multirow{9}{*}{ Patients } & \multirow{3}{*}{$\begin{array}{l}\text { Well-being pre } \\
\text { surgery (pts.) }\end{array}$} & 0.65 & $\mathrm{I} / \mathrm{I}$ & 10 & 6.4 & 1.71 \\
\hline & & & I/D & 51 & 6.39 & 2.41 \\
\hline & & & $\mathrm{D} / \mathrm{D}$ & 30 & 6.13 & 2.05 \\
\hline & \multirow{3}{*}{$\begin{array}{l}\text { Difference in well- } \\
\text { being post surgery } \\
\text { (pts.) }\end{array}$} & 0.16 & $\mathrm{I} / \mathrm{I}$ & 10 & -0.9 & 1.79 \\
\hline & & & I/D & 51 & -0.02 & 2.79 \\
\hline & & & $\mathrm{D} / \mathrm{D}$ & 30 & -1 & 2.18 \\
\hline & \multirow{3}{*}{$\begin{array}{c}\text { Time spent in } \\
\text { hospital (days) }\end{array}$} & 0.16 & $\mathrm{I} / \mathrm{I}$ & 10 & 6.7 & 2.21 \\
\hline & & & I/D & 51 & 8.75 & 5.48 \\
\hline & & & $\mathrm{D} / \mathrm{D}$ & 30 & 9.03 & 7.38 \\
\hline
\end{tabular}

The ID genotype in the ACE had no significant effect on the patients' time spent in hospital $(\mathrm{P}>0.05$; Table 2). However, time to convalescence following a surgical procedure was the shortest in patients with genotype II, and the longest in patients with genotype DD. Furthermore, patients with genotype DD did not endure surgeries as well as those with genotype II, and their well-being deteriorated to a greater extent post-surgery compared with wellbeing pre-surgery. The type of surgery had a significant impact on convalescence (Table 4). Time spent in hospital after oncological surgeries was shown to be longer than after non-oncological surgeries, irrespective of whether chemotherapy was administered. Patients' age did not significantly affect time spent in hospital or well-being (Table 3). However, older patients required more time for convalescence and home discharge, and their well-being also deteriorated to a greater extent post- surgery. It was also observed that the greater frequency with which patients practiced sports, the shorter their hospital admittance (Table 5). Furthermore, physically active patients had a better well-being post-surgery than patients doing no sports.

Table 3: Comparative analysis of well-being, and patients' convalescence.

\begin{tabular}{|c|c|c|c|c|c|c|c|}
\hline & & p & Feature & & $\mathbf{N}$ & $\overline{\mathbf{x}}$ & SD \\
\hline \multirow{8}{*}{$\begin{array}{l}\text { Healthy } \\
\text { individuals }\end{array}$} & \multirow{2}{*}{$\begin{array}{l}\text { Well-being pre- } \\
\text { physical activity } \\
\text { (pts.) }\end{array}$} & 0.09 & class & amateur & 27 & 8.22 & 1.19 \\
\hline & & & & professional & 12 & 7.5 & 1.45 \\
\hline & \multirow{2}{*}{$\begin{array}{c}\text { Difference in } \\
\text { well-being post } \\
\text { physical activity } \\
\text { (pts.) }\end{array}$} & 0.22 & & amateur & 27 & 0.04 & 1.22 \\
\hline & & & & professional & 12 & 0.58 & 1.31 \\
\hline & \multirow{2}{*}{$\begin{array}{l}\text { Well-being pre } \\
\text { physical activity } \\
\text { (pts.) }\end{array}$} & 0.66 & age & $\leq 35$ years old & 19 & 8.26 & 1.19 \\
\hline & & & & $>35$ years old & 20 & 7.75 & 1.37 \\
\hline & \multirow{2}{*}{$\begin{array}{c}\text { Difference in } \\
\text { well-being post } \\
\text { physical activity } \\
\text { (pts.) }\end{array}$} & 0.85 & & $\leq 35$ years old & 19 & 0.16 & 1.38 \\
\hline & & & & $>35$ years old & 20 & 0.25 & 1.16 \\
\hline
\end{tabular}




\begin{tabular}{|c|c|c|c|c|c|c|c|}
\hline \multirow{9}{*}{ Patients } & \multirow{3}{*}{$\begin{array}{l}\text { Well-being pre } \\
\text { surgery (pts.) }\end{array}$} & 0.49 & age & $\geq 50$ years old & 30 & 6.63 & 2.53 \\
\hline & & & & 51-65 years old & 32 & 5.97 & 2.21 \\
\hline & & & & $>65$ years old & 29 & 6.34 & 1.86 \\
\hline & \multirow{3}{*}{$\begin{array}{c}\text { Difference in } \\
\text { well-being post } \\
\text { surgery (pts.) }\end{array}$} & 0.32 & & $\geq 50$ years old & 30 & -0.13 & 2.74 \\
\hline & & & & 51-65 years old & 32 & -0.88 & 2.88 \\
\hline & & & & $>65$ years old & 29 & -0.28 & 1.81 \\
\hline & \multirow{3}{*}{$\begin{array}{l}\text { Time spent in } \\
\text { hospital (days) }\end{array}$} & 0.86 & & $\geq 50$ years old & 30 & 7.87 & 4.65 \\
\hline & & & & 51-65 years old & 32 & 8.31 & 4.82 \\
\hline & & & & $>65$ years old & 29 & 9.72 & 7.95 \\
\hline
\end{tabular}

Table 4: Comparative analysis of patients' convalescence time, well-being, administration of chemotherapy, and surgery type.

\begin{tabular}{|c|c|c|c|c|c|}
\hline & $\mathbf{p}$ & Chemotherapy & $\mathbf{N}$ & $\overline{\mathbf{x}}$ & SD \\
\hline \multirow{2}{*}{$\begin{array}{l}\text { Well-being before a } \\
\text { surgery (pts.) }\end{array}$} & 0.56 & no & 62 & 6.42 & 2.27 \\
\hline & & yes & 29 & 6.07 & 2.09 \\
\hline \multirow{2}{*}{$\begin{array}{l}\text { Difference in well-being } \\
\text { after a surgery (pts.) }\end{array}$} & 0.7 & no & 62 & -0.5 & 2.58 \\
\hline & & yes & 29 & -0.31 & 2.45 \\
\hline \multirow{3}{*}{$\begin{array}{l}\text { Time spent in the hospital } \\
\text { (days) }\end{array}$} & 0.61 & no & 62 & 7.92 & 6.08 \\
\hline & & yes & 29 & 10.1 & 5.41 \\
\hline & $\mathrm{p}$ & Surgery type & $\mathrm{N}$ & $\overline{\mathrm{x}}$ & SD \\
\hline \multirow{2}{*}{$\begin{array}{l}\text { Time spent in hospital } \\
\text { (days) }\end{array}$} & 0.03 & non-oncological & 36 & 7.03 & 4.66 \\
\hline & & oncological & 55 & 9.65 & 6.47 \\
\hline
\end{tabular}

Table 5: Comparative analysis of patients' convalescence time, well-being, and sport participation level.

\begin{tabular}{|c|c|c|c|c|c|}
\hline & $\mathbf{p}$ & Sport Participation Level & $\mathbf{N}$ & $\overline{\mathbf{x}}$ & SD \\
\hline \multirow{5}{*}{$\begin{array}{l}\text { Difference in well- } \\
\text { being after a surgery } \\
\text { (pts.) }\end{array}$} & 0.68 & none & 28 & -1.07 & 3.03 \\
\hline & & little & 33 & -0.36 & 1.82 \\
\hline & & occasional & 14 & 0.07 & 3.32 \\
\hline & & amateur & 13 & 0.08 & 2.22 \\
\hline & & professional & 3 & 0 & 1 \\
\hline \multirow{5}{*}{$\begin{array}{l}\text { Well-being before a } \\
\text { surgery (pts.) }\end{array}$} & 0.74 & none & 28 & 6.21 & 2.2 \\
\hline & & little & 33 & 6.12 & 2.12 \\
\hline & & occasional & 14 & 6.93 & 2.59 \\
\hline & & amateur & 13 & 6.54 & 2.3 \\
\hline & & professional & 3 & 5.33 & 1.53 \\
\hline \multirow{5}{*}{$\begin{array}{l}\text { Time spent in hospital } \\
\text { (days) }\end{array}$} & 0.04 & none & 28 & 10.36 & 7.58 \\
\hline & & little & 33 & 7.88 & 5.18 \\
\hline & & occasional & 14 & 8.93 & 5.27 \\
\hline & & amateur & 13 & 6.15 & 3.24 \\
\hline & & professional & 3 & 9.67 & 6.66 \\
\hline
\end{tabular}

\section{Discussion}

The main finding of this study is that patients who are more physically active and practice sports regularly, stay for a shorter time in hospital, post-surgery $(p=0.04)$. Secondly, Occurrence of allele I remained invariant between participants with high or low levels of well-being. It is asserted that certain genetic factors may influence physical performance [11]. The D/I polymorphism of the ACE gene has been extensively studied for its association with diseases and physical performance. The ACE gene, by affecting the regulation of the heart and circulatory system function, is unequivocally important for the performance of endurance exercises at high intensity [19].

Professional or high-level sporting performance is, often, associated with a high VंO2max, and is often positively correlated with the presence of allele I in the ACE gene [20]. Moreover, individuals with genotype II in the ACE gene were found to experience low blood pressure, which positively affects their endurance performance during prolonged and intense exercise 
[15]. The efficacious function of the cardiopulmonary system is necessary for both healthy individuals and post-surgery recovery [3].

Our study did not find a statistically significant relationship between the presence of allele I in the ACE gene and physical fitness and well-being post physical activity or surgical intervention, respectively. Similarly, Oelz et al. [21] also noted no effects of the polymorphism on their participants' performance; whilst Rankinen et al. [4] noted a significant association of VंO2max with genotype DD, but not with genotype II [5]. Elevated ACE was noted in deletion homozygotes in the cardiac muscle and the circulatory system in elite athletes [22]. This is related to a higher level of conversion of angiotensin I into angiotensin II, which in turn contributes to the growth of cardiomyocytes and fibroblasts. An increase in the strength of skeletal muscles and the cardiac muscle (increased mass of the left ventricle) has been demonstrated in individuals with DD and DI genotypes in the ACE gene than in individuals with genotype II in response to physical exercise during military training [16]. Other authors also observed that allele D was associated with greater strength, muscle volumes, a higher percentage of fasttwitch muscle fibers [23]. This was confirmed by a study of shortdistance swimmers in whom allele D was present more often than in a sedentary control group [24].

The adaptation of the circulatory system to high altitudes involves decreased maximal cardiac output and stroke volume. Maximal aerobic capacity is essentially determined by the matching of convective and diffusion oxygen transport systems, which can be modulated by specific pulmonary vasodilating interventions [25]. Allele D of the ACE gene was also shown to deleteriously affect heart rate, blood pressure, and arterial oxygen saturation [25]. Charu et al. [26] noted that the D/D and D/I genotypes occurred often in individuals susceptible to high altitude pulmonary edema (HAPE), and in turn, allele I was present in individuals resistant to HAPE. In a study of residents living at elevations of above $3400 \mathrm{~m}$, the occurrence of allele I was found to be significantly higher in inhabitants of high-altitude rather than low-altitude environments. These results indicate that the overrepresentation of the ACE gene may be a factor playing a fundamental role in high-altitude adaptation [27]. Notwithstanding, the DD polymorphism is associated with higher oxygen uptake, periventricular leukomalacia, or intraventricular hemorrhage [28].

An Insertion polymorphism can be also associated with a higher risk of coronary heart disease and left ventricular hypertrophy [29], whilst the presence of allele I also seems to prevent pathologies in the body by reducing the prevalence of the so-called metabolic syndrome, i.e. a clustering of risk factors associated with developing cardiovascular disease. Signs of metabolic syndrome include insulin resistance and hypertension, which decrease following the use of ACE inhibitors. Further, the DD polymorphism was shown to occur more often in women with arterial hypertension and with recognized metabolic syndrome [30].

Adaptability was confirmed where the mean muscle fiber cross-sectional area was significantly smaller and the number of capillaries per unit cross-sectional area was significantly greater in individuals with I/I genotype, which enables more efficient oxygen transport and nutrition of muscles [21]; thereby enabling more effective use of energy substrates, and adaptation of glucose catabolism enzymes [30]. Efficacious transport of nutrients and oxygen to the muscle in individuals with the I/I genotype during prolonged physical exercise may not only be exclusively associated with the efficiency of oxygen supply to skeletal muscles via the circulatory system; allele I of the ACE gene likely determines to a greater degree the induction of post-exercise responses leading to a quick attainment of homeostasis [31]. The increased effectiveness of these biochemical processes at the cellular level rationalizes the storage of other energy substrates in the body, in particular glycogen stores [16]. A study of resistance to local exercise by I/I genotype individuals highlighted that participants performed more weightlifting repetitions (using elbow flexors) [16]; indicating a positive effect of local changes on individuals with genotype I/I, not just merely on their endurance performance levels attained as a function of their more efficient cardiovascular system [24]. It has been asserted that allele I may have a positive influence on aerobic endurance, most likely manifest through local muscle performance, opposed to the central circulatory system [24]. Whilst Oelz et al. [21] noted that the presence of genotype I/I in the ACE gene may not only be relevant to the functioning of cardiovascular system, but also for aerobic and respiratory factors.

Apart from ACE, other components of the renin-angiotensin system (AGT, AGTR1, CYPR11B) have been investigated [31]. The RAS component hormones found in many human body organs, e.g. heart, kidneys, brain, and body fat, are significant for control of gene expression and cell growth. Their activation may contribute to high blood pressure, obesity, diabetes, and dyslipidemia [30], i.e. medical conditions necessitating prolonged hospitalization. It was also indicated that, in individuals resistant to physical stress, allele I co-occurs exclusively with the ET-1 genotype [26]. Furthermore, a positive correlation has been highlighted between the ACE D polymorphism and AGT 235M [25], whilst a correlation between ACE (A240T) with high-altitude pulmonary edema [32], as well as with I/D polymorphism, have been noted [33]. Due to equivocal nature of empirical studies to date, it would be highly desirable to carry out further research into genotypes of professional and amateur athletes, and, in particular, surgical patients to investigate the mechanisms of exercise/surgical tolerance, recovery, and responses to high physical stress and hypoxia.

\section{Limitations}

Although during the course of this study we performed detailed molecular and qualitative analyses, there are further data that could be collected in future studies to supplement existing measures, such as oxygen saturation or uptake, heart function, and blood pressure. This would permit a greater understanding of the physiological responses to both surgery and healthy individuals, notwithstanding issues of feasibility; this was not the primary aim of the study. A further limitation of this study was the use of self-report modalities to ascertain physical activity level and well- 
being, nevertheless, both constructs are routinely collected using such methods in clinical practice and epidemiological research. The authors would, however, recommend that objective measure of physical activity [34] being scrutinized in greater detail in future studies [35].

Based on the collected data, it was not possible to indicate a common genotype predisposing resistance to surgery or physical activity, with no statistically significant correlation between the ID polymorphism of ACE gene in either group. However, in the patient group, physical activity was conducive to shorter time to convalescence, and should be considered by clinicians and other key stakeholders in the management of such patients.

\section{References}

1. Challapalli A, Carroll L, Aboagye EO (2017) Molecular mechanisms of hypoxia in cancer. Clin Transl Imaging 5(3): 225-253.

2. Rossetti GMK, Macdonald JH, Smith M, Jackson AR, Callender N, et al. (2017) MEDEX 2015: Greater sea-level fitness is associated with lower sense of effort during himalayan trekking without worse acute mountain sickness. High Alt Med Biol 18(2): 152-162.

3. Hui D, Elsayem A, Palla S, De La Cruz M, Li Z, et al. (2010) Discharge outcomes and survival of patients with advanced cancer admitted to an acute palliative care unit at a comprehensive cancer center. J Palliat Med 13(1): 49-57.

4. Rankinen T, Bray MS, Hagberg JM, Pérusse L, Roth SM, et al. (2006) The human gene map for performance and health-related fitness phenotypes: the 2005 update. Med Sci Sports Exerc 38(11): 18631888.

5. Żmijewski P, Cięszczyk P, Ahmetov Ildus I, Gronek P, Lulińska-Kuklik E, et al. (2018) The NOS3 G894T (rs1799983) and-786T/C (rs2070744) polymorphisms are associated with elite swimmer status. Biol Sport 35(4): 313-319.

6. Karpowicz K, Krych K, Karpowicz M, Gronek P (2018) The relationship between CA repeat polymorphism of the IGF-1 gene and the structure of motor skills in young athletes. Acta Bioch Pol 65(1): 43-50.

7. Gronek P, Gronek J, Lulińska-Kuklik E, Spieszny M, Niewczas M, et al. (2018) Polygenic study of endurance-associated genetic markers NOS3 (Glu298Asp), BDKRB2 (-9/+9), UCP2 (Ala55Val), AMPD1 (Gln45Ter) and ACE (I/D) in polish male half marathoners. J Hum Kinet 64(1): 87-98.

8. Holdys J, Gronek P, Kryściak J (2013) Genetic variants of uncoupling proteins-2 and-3 in relation to maximal oxygen uptake in different sports. Acta Bich Bol 60(1): 71-75.

9. Gronek P, Holdys], Kryściak J, Stanisławski D (2013) CKM Gene G (Ncoi) Allele has a positive effect on maximal oxygen uptake in caucasian women practicing sports requiring aerobic and anaerobic exercise metabolism. J Hum Kinet 39(1): 137-145.

10. Gronek P, Holdys J, Kryściak J, Wieliński D, Słomski R (2014) Maximal oxygen uptake is associated with allele-202 A of insulin-like growth factor binding protein-3 (IGFBP3) promoter polymorphism and (CA) (n) tandem repeats of insulin-like growth factor IGF1 in Caucasians from Poland. Acta Bioch Pol 61(2): 245-252.

11. Cięszczyk P, Willard K, Gronek P, Zmijewski P, Trybek G, et al. (2017) Are genes encoding proteoglycans really associated with the risk of anterior cruciate ligament rupture? Biol Sport 34(2): 97-103.

12. Leżnicka K, Gronek P, Kurzawski M, Cięszczyk P, Malinowski D, et al. (2018) Is pain tolerance in boxers altered by nucleotide polymorphism rs6746030 in the SCN9A gene? Arch Budo 14: 71-78.
13. Gronek P, Wieliński, D, Gronek J (2015) Genetic and non-genetic determinants of aggression in combat sports. Open Life Sci 10(1): 7-18.

14. Szalata M, Słomski R, Balkó Š, Balkó I (2019) Advances in athletegenomics in 2019. Trends Sport Sci 2(26): 55-61.

15. Ahmetov I, Fedotovskaya O (2015) Current Progress in Sports Genomics. Adv Clin Chem 70: 247-314.

16. Montgomery HE, Marshall R, Hemingway H, Myerson S, Clarkson P, et al. (1998) Human gene for physical performance. Nature 393(6682): 221-222.

17. Cieszczyk P, Krupecki K, Maciejewska A, Sawczuk (2009) The angiotensin converting enzyme gene I/D polymorphism in Polish rowers. Int J Sports Med 30(8): 624-627.

18. Halmová N, Kanásová J, Šiška L (2019) Physical fitness and level of body components in the 11-15-year old population in west Slovakia. Trends in Sport Sci 1(26): 21-26.

19. Nazarov IB, Woods DR, Montgomery HE, Shneider OV, Kazakov VI, et al. (2001) The angiotensin converting enzyme I/D polymorphism in Russian athletes. Eur J Hum Genet 9(10): 797-801.

20. Myerson S, Hemingway H, Budget R, Martin J, Humphries S, et al. (1999) Human angiotensin I-converting enzyme gene and endurance performance. J Appl Physiol 87(4): 1313-1316.

21. Oelz O, Howald H, Di Prampero PE, Hoppeler H, Claassenet H, et al. (1986) Physiological profile of world-class high-altitude climbers. J Appl Physiol 60(5):1734-1742.

22. Rigat B, Hubert C, Alhenc-Gelas F, Cambien F, Corvol P, et al. (1990) An insertion/deletion polymorphism in the angiotensin I-converting enzyme gene accounting for half the variance of serum enzyme levels. J Clin Invest 86(4): 1343-1346.

23. Charbonneau DE, Hanson ED, Ludlow AT, Delmonico MJ, Hurley BF, et al. (2008) ACE genotype and the muscle hypertrophic and strength responses to strength training. Med Sci Sports Exerc 40(4): 677-683.

24. Woods D, Hickman M, Jamshidi Y, Brull D, Vassiliou V, et al. (2001) Elite swimmers and the D allele of the ACE I/D polymorphism. Hum Genet 108(3): 230-232.

25. Buroker NE, Ning XH, Zhou ZN, Li K, Cen WJ, et al. (2010) Genetic associations with mountain sickness in Han and Tibetan residents at the Qinghai-Tibetan Plateau. Clin Chim Acta 411(19-20): 1466-1473.

26. Charu R, Stopdan T, Ram RB, Khan AP, Qadar Pasha MA, et al. (2006) Susceptibility to high altitude pulmonary oedema: role of ACE and ET-1 polymorphism. Thorax 61(11): 1011-1012.

27. Droma Y, Hanaoka M, Basnyat B, Arjyal A, Neupane P, et al. (2008) Adaptation to high altitude in Sherpas: association with the insertion/ deletion polymorphism in the Angiotensin-converting enzyme gene. Wilderness Environ Med 19(1): 22-29.

28. Harding D, Dhamrait S, Marlow N, Whitelaw A, Gupta S, et al. (2003) Angiotensin-converting enzyme DD genotype is associated with worse perinatal cardiorespiratory adaptation preterm infants. J Pediatr 143(6): 746-749.

29. Páll D, Settakis G, Katona E, Zatik J, Kollár J, et al. (2004) Angiotensinconverting enzyme gene polymorphism, carotid intima-media thickness, and left ventricular mass index in adolescent hypertension. J Clin Ultrasound 32(3): 129-135.

30. Procopciuc LM, Sitar-Tăut A, Pop D, Sitar-Tăut DA, Olteanu I, et al, (2010) Renin angiotensin system polymorphisms in patients with metabolic syndrome (MetS). Eur J Intern Med 21(5): 414-418.

31. Macarthur DG, North KN (2005) Genes and human elite athletic performance. Hum Gene 16(5): 331-339 
32. Qi Y, Niu W, Zhu T, Zhou W, Qiu C (2008) Synergistic effect of genetic polymorphism of rennin-angiotensin-aldosterone system on highaltitude pulmonary edema: a study from Qinghai-Tibet altitude. Eur J Epidemil 23(2): 143-152.

33. Zhu X, Bouzekri N, Southam L, Cooper RS, Adeyemo A, et al. (2001) Linkage and association analysis of angiotensin I-converting enzyme (ACE)-gene polymorphism with ACE concentration and blood pressure. Am J Hum Genet 68(5): 1139-1148.
34. Clark CCT, Nobre GC, Fernandes JFT, Moran J, Drury B, et al. (2018) Physical activity characterization: does one site fit all? Physiol Meas 39(9): 09TR2.

35. Rankinen T, Wolfarth B, Simoneau JA, Maier-Lenz D, Rauramaa R, et al. (2000) No association between the angiotensin-converting enzyme ID polymorphism and elite endurance athlete status. J Appl Physiol 88(5): 1571-1575.

For possible submissions Click below: 